\title{
Psychosis and Rodenticides: A Case Report
}

\author{
Tenzin Tsundue, Khayati Moudgil* \\ Department of Pharmacy Practice, JSS College of Pharmacy, Udhagamandalam-643 001, The Nilgiris, Tamil Nadu, INDIA.
}

\begin{abstract}
Objective: A poison can be any substance that can be taken through any means with net production of toxicity, which may result into death and coma as well. The evolution of rodenticides through history, witnesses the large-scale use of the first and the second-generation rodenticides those are commonly found with many of the household items meant for pest control. Psychosis is a mental health issue associated with episodes of hallucinations and delusions. This leads to the patient's misinterpretation of the surrounding environment. Few literatures have been reported regarding the use of rodenticides in psychotic patients. Manifestations of rodenticide poisoning includes gastric irritations, flank pain, gastric distension etc. The management focus of rodenticide poisoning should be more prominently based on most recent updated guidelines and dose titration should be monitored on the laboratory outcomes. Monitoring is the key to remission.
\end{abstract}

Key words: Adverse Drug Reactions, Psychosis, Poison, Rodenticides, Self-Harm.

Key message: Rodenticide poisoning in psychotic patient is rarely observed and the management procedures should be based on the corresponding details of the ingested product. Continuous monitoring is as necessary for patients to avoid interactions that are life threatening. Implementation of more concrete evidence based approaches is a need of the hour.

\section{Correspondence}

Dr. Khayati Moudgil, Department of Pharmacy Practice, JSS College of Pharmacy, Udhagamandalam - 643 001, The Nilgiris, Tamil Nadu, INDIA.

Phone: $+91-9489238815$

Email: khayatimoudgil@jssuni.edu.in

DOI: 10.5530/jyp.2018.10.83

\section{INTRODUCTION}

Any substance when taken in more than the recommended quantity can lead to harm. A poison is a substance that can be ingested, inhaled or injected with resultant damage to the bodily tissues. The extent of the damage may range from an acute illness to a chronic illness that might include brain damage and consecutively coma as well as death. ${ }^{1}$ Poisons can be swallowed, absorbed through the skin, inhaled, splashed into the eyes, or injected. Medication overdose remains the most cause of poisoning. This may include over-the-counter drugs (OTCs) as well as prescriptions containing most likely medications such as the anti-depressants and antipsychotics. $^{2}$ The lists of potential poisons can be non-exhaustive as poisoning can be caused from common household items to the prespecified poisons meant for insecticidal and rodenticide purposes.

Psychosis is a mental health problem associated with hallucinations and delusions leading to the misinterpretation of the environmental surroundings. Where hallucination can be defined as a person interpreting things that aren't actually there, and delusion as imaginations of conspiracy. However, psychosis can be an etiological consequence of schizophrenia, bipolar disorder, severe depression, and drug misuse as well. ${ }^{3}$ additionally; a Meta-Analysis to study the prevalence of mental and behavioral disorders in India concluded that organic psychosis, schizophrenia and affective disorders contributed a prevalence rate of 15.4 per thousand population. ${ }^{4}$ Self-harm remains a huge threat to patients with psychotic symptoms. Furthermore, an epidemiological survey concluded patient with psychotic experiences being more prone to suicidal ideation. ${ }^{5}$

Rodenticides are toxic chemical entities meant to kill rodents, which can be commonly generalized to rats and mice. Where the toxicity may be induced from even a minute exposure to others requiring more concentration to potentiate a lethal effect. The use of rodenticides has evolved with the ages from heavy metals to anticoagulants and neuro-toxic drugs such as bromethalin that acts via the Central nervous system (CNS) ${ }^{6}$
Anticoagulants can also be classified into the first (the chronic) and the single dosed (second generation) drugs. Acting via the blockade of the Vitamin $\mathrm{K}$ cycle leading to the non-availability of essential clotting factors such as the factors II and VII. ${ }^{7}$

In this case report, we discuss a patient with history of psychosis and eventual rodenticide poisoning, the management approaches and the latest updates.

\section{CASE HISTORY}

A 21-year male patient was presented to the Intensive Care Unit (ICU) of the public secondary care hospital, Udhagamandalam with alleged history of consumption of rat killer poison following alcohol intake the same day. On assessment of the physical and the vital signs, Cardio vascular system S1S2 was normal, Respiratory system with bilateral air entry positive and per abdomen soft. Blood pressure measured 130/80 $\mathrm{mmHg}$ and pulse rate was 88 beats $/ \mathrm{min}$.

Ryle's tube was inserted through the nasal cavity and stomach wash was initiated followed by 1 pint of IVF Normal Saline, 2 pints of IVF DNS and 1 pint of IVF Ringer Lactate, IV Ranitidine $25 \mathrm{mg}$ BD and Vitamin K 20 mg IM OD.

On the next day, the patient's pulse rate measured $80 /$ minute, respiratory rate $18 /$ minute and blood pressure $110 / 70 \mathrm{mmHg}$. His partial oxygen was measured $96 \%$ in room air with fluid input and output being 1500 to $600 \mathrm{ml}$. No per oral was ordered and Injection Cefotaxime 1gm BD was initiated. On day 2 , the same therapy was followed as day one and patient had a complaint of altered sleep.

The next day, the patient was noted in a drowsy state, his pupils were equally dilated and reactive to light. Yet, the same therapy was followed and no additional treatments were administered. 
The medical history brought forward by the patient's mother signified the patient being a case of psychiatric illness associated with Paranoid schizophrenia. His medication history constituted of Tablet Imipramine, Tablet Sodium Valproate and Tablet Fluexitine since the past 6 months. Eventually, Injection Phenergan $50 \mathrm{mg}$ BD IM and Tablet Haloperidol $2.5 \mathrm{mg}$ BD were added to the ongoing therapy.

Around $2 \mathrm{pm}$ on the same day, the patient's Partial oxygen saturation (Spo2) was noted at $44 \%$ and abnormalities were observed in the cardiovascular and respiratory systems. IV Adrenaline $2 \mathrm{cc}(1 \mathrm{mg} / \mathrm{ml})$ and IV Atropine $2 \mathrm{cc}(0.6 \mathrm{mg} / \mathrm{ml})$ were consecutively administered. Yet, the patient went into a subconscious state and was not responding to any stimuli, pupils were well dilated with cardio vascular S1S2 (negative). Cardio-Pulmonary Resuscitation (CPR) was initiated with re-administration of IV Adrenaline $2 \mathrm{cc}(1 \mathrm{mg} / \mathrm{ml})$ and IV Atropine $2 \mathrm{cc}(0.6 \mathrm{mg} / \mathrm{ml})$. The Patient was still not responding and Cardio vascular system (CVS) and Respiratory system (RS) were found non palpable (negative). The patient was then intubated and ventilated with yet another dose of Injection Adrenaline $2 \mathrm{cc}(1 \mathrm{mg} / \mathrm{ml})$ and IV Atropine $2 \mathrm{cc}(0.6 \mathrm{mg} / \mathrm{ml})$.

However, the patient was non-responsive and was declared dead at $2.15 \mathrm{pm}$.

\section{DISCUSSION}

In the society of human needs, rodent control is an essential approach for the overall survival and health of the population. Where rodenticides are non-specific and rodent control compounds are used solely for the purpose of killing rodents. ${ }^{8}$ However, it exhibits clinically relevant toxicities in human as well (Table 1).

The evolutions of rodenticides have been from heavy metals in the past to the anticoagulants and non-anticoagulants in the present. The most recent advancement in anticoagulant rodenticides is the evolution of super warfarins, being highly toxic and used in concentrations low as $0.001 \% .^{9}$

Anticoagulant rodenticides are among the most commonly used rodenticides. The first generation rodenticides as the name suggest were developed earlier especially during the World War II including warfarin, coumachlor etc. The second generation includes much higher toxicity with lethal potency including bromodiolone, difenacoum etc. Mediation of effect occurs through the alterations in vitamin K cycle, net hindrance of the blood clotting factors II, VII, IX and X. Additionally increasing the capillary permeability and net resultant massive internal hemorrhage. ${ }^{10}$

Adults ingest rodenticides commonly to cause self-harm. The different manifestations of rodenticide poisoning may differ as per the active constituent of the product. Anticoagulants may present with Munchausen syndrome as well as common symptoms such as flank pain with or without hematuria, excess bleeding and menorrhagia in case of women. ${ }^{11}$ Apart from anticoagulants, the common symptoms of non-anticoagulant rodenticides include anxiety, muscle twitching, nausea, vomiting and bloody diarrhea. Certain instances of zinc containing rodenticides may result into pulmonary edema as well. ${ }^{12}$ As a whole, the verification of the type of rodenticide consumed based on history as well as symptoms are a key factor in determining the following steps for management.
The identification of the type and severity of rodenticides primarily starts from the time of first visit in ER till the state of complete remission, from vital monitoring of the heart, respiration and temperature to the sophisticated laboratory monitoring. Primary laboratory indices include the Prothrombin time (PT) and the International normalized ratio (INR) values usually evident within $24 \mathrm{~h}$ or more of exposure. Additionally, there is a drastic reduction in prothrombin, which occurs within 24-48 h of ingestion that might persist for 1-3 weeks. ${ }^{13}$ Furthermore; the major concerns lay with the second-generation anticoagulants that might hinder severe toxicity in even low doses. Because of such reasons the second-generation anticoagulants may warrant high doses of vitamin $\mathrm{K}$ and extended monitoring of PT/INR, ${ }^{14}$ for an instance, a patient was treated with prolonged vitamin $\mathrm{K}$ for several months at discharge while one other patient who was treated for only an acute phase sequentially was readmitted with massive intracranial hemorrhage. ${ }^{15-16}$ However, the sequential diagnosis needed for a management plan was not followed thoroughly.

Additional Monitoring considerations may include Random blood sugar or blood glucose levels, electrolyte levels especially in mentally altered patients, pregnancy tests in women of child bearing age, Complete blood counts, creatine phosphokinase and lactic acid in patients suspected of strychnine exposure. Also, consider abdominal plain film radiography if suspicion of a metal rodenticide. ${ }^{17}$ However, since the laboratory confirmations take at least few days for conformation, diagnosis should not be fully relied on the lab parameters alone. Prehospital care acknowledgment is necessary in each and every of the healthcare setups and in general population sites as well. Furthermore, according to one study reported oral vitamin $\mathrm{K}$ therapy of $7 \mathrm{mg} / \mathrm{kg}$ per $24 \mathrm{~h}$ divided every $6 \mathrm{~h}$ to be effective in treating coagulopathy due to brodifacoum. ${ }^{18}$

The need of detoxification depends upon the severity and the amount ingested. Patients developing renal failure may require hemodialysis while patients with severe respiratory distress may require ventilatory support. Gastric lavage is rarely indicated. However, ingestion of higher amounts and early presentation may benefit from GI wash and activated charcoal. Recent evidences suggest gastric lavage to decrease the severity of illness, improve recovery times and improve outcomes. It should be considered for life-threatening ingestions, performed within 30 to $60 \mathrm{~min} .{ }^{19}$ In some cases when the amount ingested as well as the compound is unknown, it is essential to assess PT/INR on a routine basis. Even though the effects are usually noticeable within 12-24 h, certain anticoagulants may take up to $48 \mathrm{~h}$ for effect. Additionally, a normal PT/INR even after 48-72 h may signify the event of bleeding very unlikely. Following the laboratory assessments; Vitamin $\mathrm{K}$ should be administered at a relevant calculated dose. However, the administration of vitamin $\mathrm{K}$ is not recommended empirically as delay of lab abnormalities might occur resultant missing of the seriousness of the situation. The oral route of administration should be preferred over subcutaneous, intramuscular or intravenous in regards to the better adverse event profile through the oral route. ${ }^{20}$ The dosage of Vitamin $\mathrm{K}$ depends upon the severity and the amount ingested, however large doses of rodenticide ingestion has rendered doses as high as $100 \mathrm{mg}$ and up to $400 \mathrm{mg}$ as well. Continuous monitoring of PT/INR in response to vitamin $\mathrm{K}$ can be used as a

Table 1 : Rodenticides profile.

\begin{tabular}{cccccc}
\hline RODENTI-CIDES & TYPE & ORAL INGESTION & INHALATION & OPTIC EXPOSURE & DERMAL EXPOSURE \\
\hline Warfarin & Anticoagulant & Moderate - High toxicity & Non-Significant & Non-Significant & Moderate \\
Bromethalin & Non-anticoagulant & High toxicity & High toxicity & Slight Irritation & Slight Irritation \\
Zinc phosphide & Non-anticoagulant & High toxicity & High toxicity & Low toxicity & High Irritation \\
Strychnine & Non-anticoagulant & Low toxicity & Low toxicity & Low toxicity \\
\hline
\end{tabular}


parameter for dosage adjustment. Ingestion of larger amount of the drug requires longer periods of treatment up to 3 or 4 months. Transfusion of whole blood depends upon the presenting symptoms and the laboratory assessments. Administer fresh frozen plasma or whole blood, add on to vitamin $\mathrm{K}$ to patients presenting with active bleeding. Moreover, recent evidence suggest for Vitamin $\mathrm{K}$ cessation in case of anaphylactic reactions and to opt for therapeutic plasma exchange as a second-line option. ${ }^{21}$ However, in this case, the patient was administered with empirical vitamin $\mathrm{K}$ at a dose of $20 \mathrm{mg} / 2 \mathrm{ml}$.

Psychosis is a condition associated with loss of contact with reality. The incidence of self-harm is highly associated with psychosis and clozapine remains the only FDA recognized treatment with beneficial effects against suicidal risk in schizophrenia patients. ${ }^{22}$ In this case report, the patient was treated with haloperidol. Haloperidol is a first generation antipsychotic and they are associated more with extra pyramidal side effects. The role of newer antipsychotic drugs and the overall remission lies in drug selection with not only the symptomatic controls but also in lieu of the control of suicidal ideations.

In this case report, serious drug-drug interactions were noted. Imipramine and Haloperidol had an interaction resulting in QT prolongation, ${ }^{23}$ which is a serious issue. Moreover, Fluoxetine and Imipramine shows a significant interaction with net increase in the serotonin levels and high secretion levels may induce respiratory distress. ${ }^{24}$ In the management of respiratory distress, the primary step is to obtain intravenous access followed by securing the airways through ventilation with assisted cardiac massage. On the basis of the response from the patient, administer Injection Adrenaline 1mg IV Bolus. If no response occurs still, administer Injection Atropine $3 \mathrm{mg}$ IV bolus. Patient yet non-responsive to the above therapy should then be administered with Injection Adrenaline $5 \mathrm{mg}$ IV bolus. ${ }^{25}$ The primary aim of the management should be remission and symptomatic control. Moreover, recent evidence suggest the use of $\mathrm{N}$ acetyl cysteine with Vitamin $\mathrm{K}^{26}$

\section{CONCLUSION}

More prominent and eventual implementation of guidelines in the management of patients presenting with poisoning is a need of the hour. Furthermore, additional concern should be a part of therapy designing, keeping in mind the sequential outcomes of the choice of therapy.

\section{ACKNOWLEDGEMENT}

The authors acknowledge the support and cooperation provided by the staff of Government Headquarters Hospital Ooty.

\section{CONFLICT OF INTEREST}

The authors do not report any Conflict of Interest.

\section{ABBREVIATIONS}

ER: Emergency room; OTC Over-the-counter drugs; CNS: Central Nervous System ; ICU: Intensive Care Unit; Spo2- Unit Partial oxygen saturation; CVS: Cardio Vascular System; RS: Respiratory System; PT: Prothrombin time; INR: International normalized ratio; IVF-
Intravenous Fluids ; DNS: Dextrose Normal Saline; IV: Intravenous; IM: Intramuscularly.

\section{REFERENCES}

1. Mowry JB, Spyker DA, Brooks DE, et al. UNL Environmental Health and Safety. Toxicology and Exposure Guidelines. Univ Nebrasha, Lincoln. 2002;402:28

2. Mccaig LF, Burt CW. Poisoning-Related Visits to Emergency Departments in the United States. 1999;37(7):817-26.

3. National Institute of Health and Clinical Excellence. Psychosis and schizophrenia in adults. NICE Guidel treament Manag. 2014:74-80.

4. Reddy VM, Chandrashekar CR. Prevalence of mental and behavioural disorders in India : a meta-analysis. Indian J Psychiatry. 1998;40(2):149-57.

5. De Vylder JE, Lukens EP, Link BG, Lieberman JA. Suicidal ideation and suicide attempts among adults with psychotic experiences: Data from the collaborative psychiatric epidemiology surveys. JAMA Psychiatry. 2015;72(3):219-25.

6. Huntington S, Fenik Y, Vohra R, Geller RJ. Human bromethalin exposures reported to a U.S. Statewide Poison Control System. Clin Toxicol. 2016;54(3):277-81.

7. Warmerdam M. Department of Pesticide Regulation. Assessment. 2006;(2):1-2.

8. Cefic. Guideline of Best Practise in the Use of Rodenticide Baits as Biocides in the European Union. 2013.

9. Caravati EM, Erdman AR, Scharman EJ, Woolf AD, Chyka PA, Cobaugh DJ, et al. Long-acting anticoagulant rodenticide poisoning: An evidence-based consensus guideline for out-of-hospital management. Clin Toxicol. 2007;45(1):1-22.

10. Sheet TF. Topic fact sheet. Antimicrob Fact Sheet. 2017;1-4.

11. Zahner J, Schneider W. Munchausen syndrome in hematology: Case reports of three variants and review of the literature. Ann Hematol. 1994;68(6):303-6.

12. Zhu Y, Zhang Y, Venkatesan J, Jayakumar R, Anil S, Chalisserry EP, et al. Hepatotoxicity due to zinc phosphide poisoning in two patients: Role of $\mathrm{N}$-acetylcysteine. Clin Case Reports [Internet]. 2016;4(8):768-72.

13. Toxicology C. Rodenticides. 2008;173-87.

14. Hanley JP. Warfarin reversal. J Clin Pathol. 2004;57(11):1132-9.

15. Richard R, Bruce L, Michael E, Robert E, Steven R, John B. Human Ingestion of Resulting in Rodenticide ' Superwarfarin ' Prolonged Anticoagulation in Rat Poisoning. 2015:4-5

16. Helmuth RA, McCloskey DW, Doedens DJ, Hawley DA. Fatal Ingestion of a Brodifacoum-Containing Rodenticide. 1989;20(1):25-7.

17. Nekooghadam S, Haghighatkhah H, Vaezi F, Sanei Taheri M, Moharamzad $Y$. Zinc phosphide poisoning with unusual radiologic findings. Clin Case Reports. 2017;5(3):264-7.

18. York N. Case Report Long-Acting Anticoagulant Overdose : Brodifacoum Kinetics and Optimal Vitamin K Dosing. 2000;1(1):2-7.

19. Benson BE, Hoppu K, Troutman WG, Bedry R, Erdman A, Höjer J, et al. Position paper update: Gastric lavage for gastrointestinal decontamination. Clin Toxicol. 2013;51(3):140-6.

20. Wilson SE, Watson HG, Crowther MA. Low-dose oral vitamin K therapy for the management of asymptomatic patients with elevated international normalized ratios: A brief review. CMAJ. 2004;170(5):821-4

21. Deng Y, Qiu L. Therapeutic plasma exchange: A second-line treatment for brodifacoum poisoning following an anaphylactoid reaction to vitamin K. Clin Case Reports. 2017;5(1):35-8

22. Kasckow J, Felmet K, Zisook S. Managing Suicide Risk in Patients with Schizophrenia. CNS Drugs. 2011;25(2):129-43.

23. Wenzel-Seifert K, Wittmann M, Haen E. QTc prolongation by psychotropic drugs and the risk of Torsade de Pointes. Dtsch Ärzteblatt Int. 2011;108(41):687-93.

24. Ferraro L, Fuxe K, Agnati L, Tanganelli S, Tomasini MC, Antonelli T. Modafinil enhances the increase of extracellular serotonin levels induced by the antidepressant drugs fluoxetine and imipramine: A dual probe microdialysis study in awake rat. Synapse. 2005;55(4):230-41.

25. Ministry of Health Government of Fiji Islands. Emergency Drug Guidelines. 2008:1-150

26. Bhat S, Kenchetty KP. N-Acetyl Cysteine in the Management of Rodenticide Consumption - Life Saving. 2015;9(1):OC10 